\title{
PHENOLIC COMPOUNDS OF Trapa maeotica
}

V. U. Okonenko, V. I. Litvinenko, and A. I. Tikhonov

UDC 547.972

We have made a phytochemical study of Trapa maeotica G. Woron, family Hydrocaryac eae collected in the flood plains of the island of Khortitsa, Zaporozhe oblast, in the flowering period. The plant had not been studied previously.

The qualitative composition of the phenolic compounds, according to two-dimensional paper chromatography in the systems 1) butanol-acetic acid-water (4:1:2) and 2) 15\% acetic acid is represented by nine substances. Qualitative reactions showed that substances A, B, C, D, E, and F are flavonoids. The flavonoid glycosides in the alcoholic extracts were hydrolyzed with $5 \%$ hydrochloric acid for $2 \mathrm{~h}$. The aglycones were isolated and identified as quercetin and kaempferol.

The glycosides were separated by sorption column chromatography on Kapron, elution being performed with mixtures of ethanol and water. Fractions $25-30$ yielded substance $\mathrm{B}, \mathrm{mp} 177-180^{\circ} \mathrm{C},[\alpha]_{\mathrm{D}}-$ $179^{\circ}$ (c 0.1 ; ethanol) $\lambda_{\max } 350,265,255 \mathrm{~nm}$, with sodium acetate $395 \mathrm{~nm}$, with zirconyl chloride $430 \mathrm{~nm}$, with alkali $405 \mathrm{~nm}$, and with boric acid $390 \mathrm{~nm}$.

The acid hydrolysis of substance B with $5 \%$ hydrochloric acid for $2 \mathrm{~h}$ gave quercetin (yield $\sim 45 \%$ of the weight of the glycoside). The carbohydrate moiety contained glucose and rhamnose in a ratio of $1: 1$.

On stepwise hydrolysis, no intermediate products were detected. Enzymatic hydrolysis with rhamnodiastase led to the isolation of quercetin and a biose consisting of glucose and rhamnose.

Thus, the glycoside under investigation is quercetin 3-rhamnoglucoside and could be identified with rutin. However, chromatographically it did not coincide with rutin in respect of $\mathrm{R}_{f}$ values: substance $\mathrm{B}$ 0.75 (1) and 0.56 (2); rutin from Sophora japonica 0.34 (1) and 0.57 (2).

Significant differences were also observed in other properties: optical rotation, melting point, etc., and therefore it may be assumed that the glycoside obtained is new.

By polarimetric analysis in comparison with authentic rutin and isorutin, we established that this glycoside is quercetin 3-O- $\beta-\mathrm{D}-$ glucopyranosyl-6-O- $\alpha-\mathrm{L}-\mathrm{rhamnofuranoside.} \mathrm{To} \mathrm{distinguish} \mathrm{it} \mathrm{from} \mathrm{other}$ rhamnoglucosides [1] we propose to call it neorutin. Consequently, one more isomer of rutin, the theoretical number of which may amount to 16 , has been obtained.

\section{LITERAT URE CITED}

1. V. I. Litvinenko and T. P. Nadezhdina, Rast. Res., 4, 68 (1968).

Zaporozhe Medical Institute. Khar'kov Scientific-Research Institute of Pharmaceutical Chemistry. Translated from Khimiya Prirodnykh Soedinenii, No. 4, pp. 530-531, July-August, 1971. Original article submitted March 18, 1971.

- 1973 Consultants Bureau, a division of Plenum Publishing Corporation, 227 West 17th Street, New York, N. Y. 10011. All rights reserved. This article cannot be reproduced for any purpose whatsoever without permission of the publisher. A copy of this article is available from the publisher for \$15.00. 